\title{
Alain Cullière, Dans le sillage de Robert Gamier, la tragédie «Psamménite» de Pierre et Baptiste Marye (1603)
}

\section{Filippo Fassina}

\section{(2) OpenEdition \\ Journals}

\section{Edizione digitale}

URL: http://journals.openedition.org/studifrancesi/9831

DOI: 10.4000/studifrancesi.9831

ISSN: 2421-5856

\section{Editore}

Rosenberg \& Sellier

\section{Edizione cartacea}

Data di pubblicazione: 1 octobre 2007

Paginazione: 428

ISSN: 0039-2944

\section{Notizia bibliografica digitale}

Filippo Fassina, «Alain Cullière, Dans le sillage de Robert Gamier, la tragédie «Psamménite» de Pierre et Baptiste Marye (1603)», Studi Francesi [Online], 152 (LI | II) | 2007, online dal 30 novembre 2015, consultato il 09 janvier 2021. URL: http://journals.openedition.org/studifrancesi/9831 ; DOI: https:// doi.org/10.4000/studifrancesi.9831

Questo documento è stato generato automaticamente il 9 janvier 2021.

\section{cc) (†)}

Studi Francesi è distribuita con Licenza Creative Commons Attribuzione - Non commerciale - Non opere derivate 4.0 Internazionale. 


\title{
Alain Cullière, Dans le sillage de Robert Gamier, la tragédie «Psamménite» de Pierre et Baptiste Marye (1603)
}

\author{
Filippo Fassina
}

\section{NOTIZIA}

ALAIN CULLIÈRE, Dans le sillage de Robert Gamier, la tragédie «Psamménite» de Pierre et Baptiste Marye (1603), «Bibliothèque d'Humanisme et Renaissance», LXVIII, 1 (2006), pp. 87-107.

1 Lo studioso analizza la tragedia Psamménite dei fratelli Marye, pièce in quattro atti in alessandrini e pubblicata nel 1603, il cui soggetto è tratto dal terzo libro delle Storie di Erodoto. Cullière sottolinea che l'importanza di quest'opera è dovuta soprattutto al fatto che è stata composta a due mani, senza che tuttavia si riesca a distinguere le parti composte da un autore da quelle composte dall'altro. Della tragedia vengono esaminate la struttura, lo stile, la caratterizzazione dei personaggi e l'intreccio, con particolare attenzione agli interventi che maggiormente si discostano dalla fonte, come l'aggiunta del duplice suicidio finale. Il rapporto con Garnier, secondo Cullière, risulta evidente soprattutto se si considerano le tragedie Porcie e Les Juives, con le quali è strutturato un confronto preciso di immagini e personaggi (approfondito in un'appendice che contiene una serie di raffronti). I richiami intertestuali sono continui, ma nella tragedia dei fratelli Marye si nota un ripetersi di scene e di schemi psicologici che non trova riscontro in Garnier e che, secondo lo studioso, rappresenta un difetto della pièce in questione. Altro elemento di critica riguarda la ripresa di alcune scene di Garnier, che spesso vengono inserite in modo incoerente nell'intreccio di Psamménite. Dal punto di vista dell'adesione al modello tragico, l'autore evidenzia una relativa fedeltà, benché siano presenti vistosi elementi di innovazione, come la divisione in quattro atti, al posto dei classici cinque e la disposizione degli atti e dei cori che sembrerebbe 
prediligere un equilibrio estetico piuttosto che l'adesione ai modelli classici. Anche le unità di tempo e di luogo sono trattate in modo decisamente libero. La conclusione a cui giunge Cullière è che la pièce è un «travail scolaire», che tralascia approfondimenti psicologici o caratterizzazioni senecane dei personaggi, risultando così poco complessa e più legata a un modello storico che a uno letterario. 